\title{
ANÁLISE DOS MODELOS DE TOMADA DE DECISÃO SOB O ENFOQUE COGNITIVO
}

\author{
ANALYSIS OF MODELS OF DECISION MAKING \\ IN THE COGNITIVE APPROACH
}

\section{Breno A. Diniz Pereira' ${ }^{1}$, Mauri Leodir Lobler ${ }^{2}$ e Eugênio de Oliveira Simonetto ${ }^{3}$}

\begin{abstract}
Resumo
A racionalidade vem sendo definida a partir dos gregos como uma das principais características que distingue o homem dos outros animais. A influência dos gregos, como Platão e Aristóteles, e dos filósofos empiristas/racionalistas, como Descartes e Thomas Hobbes, foram marcantes para a formação dos modelos de tomadas de decisão nas organizações propostas por Simon, Allison e Lindblon. Assim, este trabalho tem o objetivo de identificar os principais modelos de tomada de decisão e verificar como os aspectos cognitivos podem afetar o comportamento dos agentes envolvidos no processo. Os resultados demonstram que não há como negligenciar os fatores subjetivos e os diferentes estilos cognitivos na decisão, pois há um sistema de relações entre os elementos de natureza objetiva e os elementos de natureza subjetiva, prevalecendo o predomínio da influência dos valores dos decisores envolvidos, o que é visto como elemento motivador da decisão.
\end{abstract}

Palavras-chave: Cognição; Tomada de decisão; Modelos, Teoria organizacional.

1 Doutor em Administração (UFRGS). Professor do Programa de Pós-Graduação em Administração e do Departamento de Ciências Administrativas (UFSM). E-mail: professorbreno@terra.com.br

2 Doutor em Administração (UFRGS). Professor do Programa de Pós-Graduação em Administração e do Departamento de Ciências Administrativas (UFSM). E-mail: mllobler@gmail.com

3 Doutor em Administração (UFRGS). Professor do Centro Universitário Franciscano (UNIFRA). E-mail: eosimonetto@gmail.com 


\begin{abstract}
The rationality has been defined from the Greeks as one of the main characteristic that distinguishes man from the other animals. The Greeks 'influence like Plato and Aristotle and the philosophers empiricist / rationalist, as Descartes and Thomas Hobbes, were remarkable for the formation of models of decision making in organizations proposed by Simon, Allison and Lindblon. This study aims to identify the mainly decisionmaking models and check how the cognitive aspects can affect the behavior of the agents involved in the process. The results show that there is no way to overlook the subjective factors, the different cognitive styles in the decision, there is a system of relations between the elements of nature objective and subjective elements, whichever is the predominant influence of the values of decision makers involved, which is seen as a motivator for the decision.
\end{abstract}

Keywords: Cognition; Decision making, Models, Organizational theory.

\title{
1 Introdução
}

Nas últimas décadas, o estudo social das ciências assinalou que as revoluções científicas não podem explicar-se unicamente pelo aparecimento de uma teoria melhor, valendo-se, para isso, somente de critérios científicos. Os fatores que fazem com que uma comunidade eleja uma teoria como a mais adequada parecem ir além das evidências empíricas e da necessidade teórica (MORIN, 1987). A primeira implicação dessa proposta é que diversos conjuntos de fatos estudados, foco de atenção científica, organizações do conhecimento e interpretações do mundo são congruentes com o que chamamos de ciência. Tanto a ciência como a cultura são processos construtores de e construídos por processos sociais (BURREL; MORGAN, 1979).

O ser humano, ao desempenhar qualquer papel na sociedade ou nas organizações, procura agir de acordo com modelos construídos ao longo de sua vida (experiências/vivências). Estes modelos são utilizados para determinar suas atitudes, escolhas pessoais e a seleção das ações conscientes ou inconscientes, para realizar uma determinada tarefa.

Nas organizações, essas escolhas são constantes, tanto que alguns autores, como Ansoff (1977), Simon (1979a), Braga (1988) e Morgan (1996), declaram que a essência das atividades administrativas é, fundamentalmente, um processo de tomada de decisão e este, por sua vez, uma atividade eminentemente humana. Nesse sentido, o estudo do processo de tomada de decisão toma-se essencial para o entendimento do desenvolvimento e das formas de atuação das organizações.

Um segundo fator para o estudo de tomada de decisões está no fato de que a ambição da Administração Científica era conhecer as variáveis envolvidas na dinâmica organizacional e, então, controlá-las para atingir o objetivo maior das organizações e dos indivíduos: a maximização das riquezas dos proprietários. Um dos estudos sobre tomada de decisão foi desenvolvido por Simon (1979a), para quem o ato de decidir é essencialmente uma ação humana, comportamental e envolve a seleção consciente ou inconsciente de determinadas ações, entre aquelas que são fisicamente possíveis para o agente e para aquelas pessoas sobre as quais ele exerce influência e autoridade. Processos administrativos são processos decisórios, pois consistem no isolamento de certos elementos nas decisões, dos membros da organização, no estabelecimento de métodos de rotina para solucionar e determinar esses elementos e na sua comunicação àqueles por eles afetados.

Rev. Adm. UFSM, Santa Maria, v. 3, n. 2, p. 260-268, mai./ago. 2010 
Dessa forma, autores como Ansoff (1977), Simon (1979b), Leitão (1993) e Motta (1996) são unânimes na afirmação de que a avaliação do processo decisório e a tomada de decisão passam pela abordagem idealizada, que compara o ideal e o que realmente ocorre, o real.

Por isso, pode-se dizer que a teoria da decisão tem sido preponderantemente prescritiva e normativa, pois procura estabelecer regras e modelos que são sugeridos para serem seguidos. Assim, a tomada de decisão, no ponto de vista administrativo, é muitas vezes confundido como um processo funcionalista e de razão utilitária.

Segundo Amatucci (1995), o sujeito desta razão utilitária faz de sua vida a maximização de valores econômicos, atitude esta que, pelo concurso da mão invisível, seja na economia de Smith, seja na ética de Mill, promove o bem-estar harmônico de toda a sociedade. Fica também redefinido o sentido Aristotélico de "homem racional", para o "homus economicus" (que Taylor recebe da economia e transmite à administração em seus princípios). Se a razão moderna é calculo utilitário, adequação de meios a fins, preocupada com a utilidade daquilo com que se detém, com a missão de servir de ferramenta (ao sujeito) para a dominação da natureza, então ela está em seu lugar por excelência, dentro do funcionalismo.

Entretanto, estudos têm apontado que o processo de tomada de decisão não está somente relacionado ao modelo racional. Diversos autores, como Lindblom (1959) e Alisson (1969), demonstraram que o processo de tomada de decisão está baseado em fatores cognitivos e de natureza institucional. Assim, este trabalho tem o objetivo de identificar os principais modelos de tomada de decisão e verificar como os aspectos cognitivos podem afetar o comportamento dos agentes envolvidos no processo.

O trabalho está dividido em cinco partes. Na primeira até a terceira parte, serão expostos os modelos de tomada de decisão da racionalidade ilimitada (modelo neoclássico), racionalidade limitada (Simon) e o modelo incremental (Lindblom). Nesses tópicos serão apresentadas as origens, suas características, sua aplicabilidade na administração, bem como suas limitações. Na quarta parte, buscar-se-á verificar o processo de cognição nos três modelos, com o intuito de conseguir uma melhor aplicabilidade dos modelos existentes. Por fim, serão trabaIhadas as conclusões finais deste trabalho, expondo algumas sugestões para futuras pesquisas.

\section{Modelo da racionalidade ilimitada}

Para a administração, o conceito de racional é utilizado para denominar uma ação praticada pelo indivíduo e sua relação com referência aos fins pretendidos. Tomando o aspecto mais evidente, o termo racional refere-se a uma relação entre meios e fins ou, mais precisamente, à adequação dos meios usados aos fins propostos. O adjetivo racional só se aplica aos meios, os únicos que podem ser escalonados, técnica e cientificamente, em relação a um padrão unívoco, quaisquer que sejam as medidas utilizadas. Dado que os fins são determinados valorativamente, é extremamente difícil chegar-se a um acordo quanto à sua racionalidade, uma vez que a um fim sempre se pode contrapor outro, baseado em outro sistema de valores.

Já a operacionalização do termo racional na administração ocorre com a racionalidade burocrática de Weber (1963). Para o autor, o raciocínio burocrático determina uma lógica mecânica na qual a razão é determinada pela técnica. Esta técnica é validada quando há o cumprimento dos objetivos propostos à organização, com execução de tarefas, segundo regras calculáveis e sem relação com as pessoas. A burocracia promove, naturalmente, um modo de vida "racionalista", pois é o meio de transformar uma ação comunitária em ação societária, racionalmente ordenada. 
A burocracia tem um caráter "racional": regras, meios, fins e objetivos dominam sua posição. Entretanto, no entender de March e Simon (1979), esse tipo de racionalidade objetiva sugere que o indivíduo atuante ajuste seu comportamento a um sistema integrado, por meio: a) de visão panorâmica das alternativas de comportamento antes da tomada de decisão; b) da consideração de todo o complexo de consequências que advirão da cada escolha; c) da escoIha, tomando o sistema de valores como critério, de uma alternativa entre todas aquelas disponíveis.

A racionalidade requer um conhecimento completo e inalcançável das consequências exatas de cada escolha. Na realidade, o ser humano possui apenas um conhecimento fragmentado das condições que cercam sua ação, e ligeira percepção das regularidades dos fenômenos e das leis que the permitiram gerar futuras consequências com base no conhecimento das circunstâncias atuais.

A fim de melhor compreender o tema, Simon, em 1989, desenvolveu o trabalho intitulado "A razão nas coisas humanas", buscando elucidar as diferentes perspectivas da racionalidade. Argumentou que o processo de decisão racional é derivado das ciências econômicas e da estatística e que esse tipo de racionalidade está baseada no modelo neoclássico de racionalidade objetiva, em que o administrador tem completa capacidade de tomar a decisão que maximizará os seus desejos, e as organizações, os lucros.

As percepções de Simon (1979b) quanto à forma em que as limitações do pensamento humano afetam o funcionamento das organizações geraram um nexo fundamental entre a economia e a teoria organizacional. Suas ideias foram de encontro à visão dos economistas neoclássicos, que tinham os seres humanos como tomadores de decisões totalmente racionais, e da empresa como pouco mais do que um veículo para um empresário voltado completamente à maximização dos lucros. Simon via o homem como um ator econômico bombardeado por escolhas e decisões, mas possuindo um estoque limitado de informações e capacidades de processamento. De acordo com Simon (1979b), as pessoas são "intencionalmente racionais, apenas de forma limitada". Ele via a luta do homem para assimilar avalanches de informações e para compensar sua incapacidade de aprender todas as decisões disponíveis selecionando opções, suficientemente boas, em lugar de soluções ótimas postuladas pelos economistas neoclássicos.

\section{$3 \mathrm{O}$ modelo da racionalidade limitada}

A maioria dos modelos de processo decisório, apresentados na literatura da área, guarda em comum características semelhantes ao modelo da racionalidade limitada descrito por Simon (1965). Devido à importância de seu trabalho, Herbert Simon recebeu o prêmio Nobel de Economia, em 1978, por sua "teoria da racionalidade limitada". O autor preocupou-se em considerar a importância dos aspectos cognitivos envolvidos no processo decisório tendo em vista os limites da racionalidade humana. Ele construiu, assim, uma teoria administrativa baseada nos limites da racionalidade do homem administrativo, que se opõe à racionalidade do homem econômico (MOTTA, 1998).

A racionalidade limitada é assim explicada por Simon (1979b, p. 505): 
O comportamento real não alcança racionalidade objetiva, pelo menos por três aspectos diferentes:

(1) A racionalidade requer um conhecimento completo e antecipado das conseqüências resultantes de cada opção. Na prática, porém, o conhecimento das conseqüências é sempre fragmentário.

(2) Considerando que essas conseqüências pertencem ao futuro, a imaginação deve suprir a falta de experiência em atribuir-lhes valores, embora estes só possam ser antecipados de maneira imperfeita.

(3) A racionalidade pressupõe uma opção entre todos os possíveis comportamentos alternativos. No comportamento real, porém, apenas uma fração de todas essas possíveis alternativas é levada em consideração.

Diante das limitações de tempo e conhecimento, entre outras, o indivíduo, impossibilitado de encontrar a decisão ótima, busca a mais adequada tendo em vista as condições disponíveis. Ele se contenta com o satisfatório em detrimento do ótimo. Um claro exemplo de decisão satisfatória e decisão ótima é apresentado por March e Simon (1967), o qual diz que aos humanos não interessa encontrar a agulha mais pontuda em um palheiro para fazer uma costura (ótima), e sim uma agulha suficientemente pontuda que dê para efetuar tal costura (satisfatória).

Segundo March e Simon (1967), a tomada de decisão vai muito além do momento de escolha, compreendendo outras etapas importantes. Segundo ele, a tomada de decisão envolve três principais fases:

(1) achar ocasiões para tomar uma decisão;

(2) achar possíveis cursos de ação, escolhendo entre eles;

(3) avaliar escolhas passadas.

O autor ressalta que os indivíduos passam uma grande parte do seu tempo pesquisando o ambiente econômico, técnico, político e social, tentando identificar novas condições que chamam por novas ações, buscando inventar, desenhar e desenvolver possíveis cursos de ação para lidar com uma situação que necessita de uma tomada de decisão; e gastam uma pequena parcela do seu tempo escolhendo entre alternativas. Por outro lado, gastam um moderado tempo avaliando decisões já tomadas, como parte de um ciclo repetitivo que os leva a novas decisões.

\section{Modelo do incrementalismo de Lindblom}

Lindblom (1959) propõe o modelo incremental, que visualiza o processo decisório sob uma perspectiva política, com suas limitações e fragmentações. Esse modelo afasta-se radicalmente do modelo racional: a escolha de uma decisão se faz sem especificação prévia de objetivos ou valores, discutem-se ações concretas, e cada um atribui às ações os fins e valores da forma como os percebe ou deseja. Logo, o critério de escolha de uma ação relaciona-se com o grau de acordo que ela suscita, e não com sua contribuição à satisfação dos objetivos preexistentes.

O modelo incremental, como o próprio nome diz, envolve uma "política de pequenos passos", sem as mudanças drásticas do modelo racional. Os tomadores de decisão procuram um resultado satisfatório, mais do que atingir situações ideais, e aceitam a possibilidade de revisão contínua das ações tomadas. 
Examinando a problemática do processo decisório do ponto de vista da natureza dos problemas que são propostos ao administrador, classificando-os em simples e complexos, Lindblom propõe que:

\footnotetext{
a)em questões de natureza simples, as decisões são racionais, dentro das mesmas características do modelo de homem econômico, pois, nestes casos, é possível considerar todas as variáveis intervenientes e o problema de valores é restrito;

b) em se tratando de problemas de natureza complexa, os administradores abandonam a racionalidade e utilizam um modelo pelo autor denominado method of sucessive limited (branch method).
}

A ideia do autor, em questões de natureza simples, enquadra-se dentro da classificação de decisões programadas propostas por Simon. Quanto ao segundo aspecto - problemas de natureza complexa - identifica-se a impossibilidade do administrador seguir um modelo racional.

Entre outras características, o method of successive limited comparisons visualiza o fato de que as decisões não pertencem a um comportamento estanque, que o tomador de decisões não pode ignorar os valores e interesses envolvidos, que toda decisão tem efeitos subjacentes sobre outras decisões. Uma decisão conduz a outra que depende de uma decisão passada ou outras concorrentes, o que, por seu turno, influencia decisões futuras. Esta complexidade de relação, a incapacidade de conhecer todas as alternativas, visualizar todas as consequências, as limitações de tempo, as pressões do ambiente etc., levam o administrador a escolher, segundo o autor, dentro de um processo de sucessivas aproximações em direção ao objetivo desejado, inserido em um quadro onde nem sempre as variáveis são conhecidas ou controláveis, influenciando por julgamentos de valor.

Com suporte da teoria, algumas conclusões podem ser retiradas:

a) o tomador de decisões, em geral, não escolhe dentro do conceito de racionalidade objetiva proposta pela teoria do homem econômico;

b) o tomador de decisões escolhe visando a atingir resultados satisfatórios, esforçandose para ser racional sem, no entanto, conseguir, face às limitações de informações e de tempo;

c) o tomador de decisões não pode isolar, em seus atos, julgamentos subjetivos e julgamentos de valor;

d) em questões complexas, o administrador decide na dúvida, lutando com a incerteza, em sucessivas tentativas, comparando resultados e ajustando novas decisões;

e) as consequências pertencem ao futuro, e o tomador de decisões aloca valores, considerando o momento, a condição presente, supondo razoável estabilidade;

f) os administradores tomam decisões sem clarificar os objetivos. Não existe distinção entre meio e fim (ao contrário de Simon);

g) ajustamentos incrementais das mudanças.

Para Lindblom, tomam-se decisões incrementais. As pessoas não percorrem todo o processo de busca de uma solução ótima, elas mudam tomando decisões incrementais do comportamento anterior. As decisões são descritivas e normativas (é melhor que seja assim). Passa-se a admitir é boa quando há um consenso trabalhado. As críticas ao modelo dizem que esse modelo somente é feito em ambiente "estáveis". 


\section{A cognição nos modelos de tomada de decisão}

A cognição preocupa-se com o como as pessoas processam e transformam as informações que recebem e a posterior utilização desta. Os psicólogos cognitivistas do processamento da informação geralmente analisam a maneira como as pessoas solucionam difíceis tarefas mentais e constróem modelos para essas explicações.

Neste trabalho, será analisado como se deu a utilização da cognição nos diferentes modelos de tomada de decisão, analisando-se, num primeiro momento, a sua utilização no modelo considerado racional; após, o modelo de Simon e, por último, o modelo proposto por Lindblom.

\section{a) Modelo racional}

No modelo racional estão reunidas as abordagens que admitem que aquele que toma a decisão possui um conhecimento completo e preciso das consequências de cada escolha. (MARCH; SIMON, 1967).

Essas abordagens, inspiradas na teoria econômica, procuram maximizar a função objetiva no sentido do lucro máximo; e, na teoria racionalista, procuram unicamente atender os objetivos da organização. Elas são estritamente racionais e normativas, muito rígidas e irrealistas.

Taylor e seus discípulos, mesmo que eles não tenham se interessado diretamente pelo assunto decisão, nos seus estudos concernentes à organização científica do trabalho, pressupõem um hiperracionalismo da decisão. A fragmentação do tempo proposta por esta escola é o reflexo de uma concepção implícita de fragmentação da decisão.

Em sequência, a teoria da administração, que nasce apadrinhada por um conjunto de valores funcionais e mecanicistas, tende a descrever o processo de decisão como algo eminentemente racional.

Nessa perspectiva, a cognição, os estilos cognitivos do decisor, não possui espaço para ser debatida. O racionalismo nega o conflito de interesses, as pressões exercidas sobre o homem pelos seus próprios limites, o papel do conhecimento, as reações afetivas e os valores do ser envolvido na decisão.

O comportamento racional do homem é compreendido como aquele que, distanciado dos sentimentos e das paixões, pode examinar, à luz da inteligência, os melhores meios de atingir um objetivo, quer dizer, submetido às exigências da razão.

\section{b) Modelo de Simon}

As abordagens racionais foram fortemente atacadas por Simon, que reconhece que, apesar dos limites simplistas e criticáveis, introduz-se nos estudos os limites do ideal racional.

As contribuições de Simon e seus seguidores sobre a tomada de decisões nas organizações são um marco referencial para o estudo. Esses trabalhos são a base para o estudo de quase todos os trabalhos posteriores referentes ao assunto.

Simon inclui no cálculo racional, variáveis irracionais e admite que o comportamento "provável" permitiu aplacar o rigor do comportamento "infalível". Ele e seus seguidores provaram definitivamente que o comportamento não é racional, rejeitando o conceito de otimização e adotando o de satisfação.

Neste momento, pode-se notar que os diferentes estilos dos decisores podem influenciar a decisão tomada. Simon (1965), em Comportamento Administrativo, reconhece a influência das variáveis psicossociais como suscetíveis de influenciar os decisores no momento da 
tomada de decisão. As variáveis inicialmente consideradas por ele são: a educação, o meio social e os problemas afetivos.

Alguns anos mais tarde, na obra As organizações, March e Simon (1979) tratam da descentralização das decisões. A descentralização considera os aspectos cognitivos do indivíduo e de sua capacidade de reter um número limitado de informações de uma vez. O procedimento implica na substituição de uma realidade complexa por uma realidade mais simples, para poder ser processado pelo "espírito" humano e superar as barreiras dos limites deste ser. Eles colocam em evidência os conflitos que podem surgir e os aspectos afetivos deste conflito.

Quando se reconhece que os estilos cognitivos dos decisores influenciam na escolha, percebe-se, assim, a decisão como um processo ligado à personalidade e à história pessoal do decisor, que possui suas características individuais: personalidade, motivações, experiências, habilidades, modo de raciocínio, julgamento intuição, criatividade etc.

A atividade mental é baseada nas duas dimensões de um "filtro", determinando de maneira dinâmica um modo de percepção e um modo de interpretação da informação.

\section{c) Modelo de Lindblom}

Neste terceiro modelo, são congregadas as abordagens da tomada de decisão que admitem que as consequências de cada escolha pertencem a um subconjunto de todas as consequências possíveis. A pessoa que toma a decisão não pode atribuir probabilidades definidas no que diz respeito a aparição de consequências particulares.

O decisor é um ser político, jogando com a informação e a palavra como meio de influência.

A abordagem adaptativa de Lindblom (1959), ligando a ciência política e o processo de decisão, coloca em evidência a natureza política do comportamento organizacional e se opõe às concepções mais tradicionais do processo de decisão organizacional. Lindblom parece abandonar a referência ao princípio de racionalidade, mesmo limitada, e adota uma concepção descritiva e puramente instrumental.

A distinção entre fins e meios parece-lhe um exercício analítico, pois os valores, os princípios de ação e mesmo os objetivos não são geralmente explícitos na escala política. A análise dos problemas e soluções é limitada pela impossibilidade de levar em conta todas as principais soluções possíveis, de avaliar importantes consequências potenciais e considerar a importância dos valores e subjetividade do decisor.

\section{Conclusão}

Por muito tempo, a tradição filosófica racionalista considerou as emoções e os sentimentos elementos perturbadores e rivais da razão. Em 1994, o neurologista português Antônio Damásio lançou o livro $O$ erro de Descartes, onde desenvolveu a hipótese segundo a qual as emoções exercem papel fundamental na tomada de decisões.

Ao examinar casos históricos de lesões no lobo frontal esquerdo e alguns de seus pacientes com traumas cerebrais mais localizados, Damásio constatou que a perda da habilidade de sentir emoções prejudicou profundamente a vida dessas pessoas. Embora elas apresentassem um desempenho normal em descrições verbais e nos cálculos matemáticos, não conseguiam sequer decidir em que restaurante deveriam almoçar.

Assim, é da interação entre estes dois subsistemas que emergirá pouco a pouco um conjunto de elementos primários de avaliação. Alguns, como os "objetivos" (ou fins a atingir) 
dos decisores, têm uma natureza intrinsecamente subjetiva, porque são próprios ao seu sistema de valores.

As características das ações, por sua vez, têm uma natureza de base mais objetiva (mais concreta). Observa-se, contudo, que objetivos e características são importantes elementos de avaliação, os quais jogam um papel de certa forma complementar no processo de construção das preferências dos decisores, sem que se possa afirmar, a priori, que um é mais fundamental que outro.

Um processo de decisão é um sistema de relações entre elementos de natureza objetiva e elementos de natureza subjetiva. Este sistema é indivisível e, portanto, quando se enfoca processo decisório não se pode negligenciar nenhum destes dois aspectos. Se for verdade que a procura da objetividade seria uma preocupação importante, é crucial não esquecer que a tomada de decisão é, antes de tudo, uma atividade humana, sustentada na noção de valor, e que o cognitivismo ajudará a entender este processo, em que a subjetividade está onipresente e é o motor da decisão.

\section{Referências bibliográficas}

ALISON, G. T. Modelos conceituais e a crise dos mísseis em cuba. Public Administration Review, v. 63, n. 3, p. 689-718, Sep. 1969.

AMATUCCI, M. Estudo sobre a racionalidade na teoria administrativa. São Paulo: FGV/EAESP, 1993.

ANSOFF, H. I. Estratégia empresarial. Trad. Antônio Z. Sanvicente. São Paulo: McGraw-Hill, 1977.

BRAGA, N. O processo decisório em organizações brasileiras. Comportamentos Comunicativos, Rio de Janeiro, v. 22, n. 4, p. 34-51, out./dez. 1988.

BURRELL, G.; MORGAN, G. Sociological paradigms and organizational analysis. London: Heinemann, 1979.

LEITÃO, S. P. A decisão na academia. Rev. Adm. Pública, Rio de Janeiro, v. 27, n. 1, p. 69-86, jan./ mar. 1993.

LINDBLOM, C. The science of muddling-through. Public Administration Review, v. 19, n. 1, p. 79-88, 1959.

MARCH, J. G.; SIMON, H.A. Teoria das organizações. Rio de Janeiro: Fundação Getúlio Vargas, 1967.

. Teoria das Organizações. 4. ed. Rio de Janeiro: Fundação Getúlio Vargas, 1979.

MORGAN, G. Imagens da organização. Trad. Cecília W. Bergamini, Roberto Coda. São Paulo: Atlas, 1996.
MORIN, E. O método III: o conhecimento do conhecimento. Lisboa: Europa-América, 1987.

MOTTA, P. R. Gestão contemporânea: a ciência e a arte de ser dirigente. 6. ed. Rio de Janeiro: Record, 1996.

Gestão contemporânea: a ciência e a arte de ser dirigente. Rio de Janeiro: Record, 1998.

SIMON, H. A. Comportamento administrativo: estudo dos processos decisórios nas organizações administrativas. 3. ed. Rio de Janeiro: Ed. da FGV, 1979a. 278p.

Rational decision making in business organizations. The American Economic Review. p. 493-513, Set. 1979b.

$\frac{1}{1989}$. A razão das coisas humanas. Lisboa: Gradiva,

WEBER, M. Ensaios de sociologia. In: GERT, H. H.; MILLS, C. W. (Org.) 2. ed. Rio de Janeiro: Zahar, 1963. Parte I, cap. IV (a política como vocação), p. 97-153 e parte II, cap. VIII (burocracia). p. 229-282. 